05

\title{
О механизме смазочного действия присадок наноалмазов детонационного синтеза в смазочных композициях
}

\author{
() А.А. Шепелевский, ${ }^{1}$ А.В. Есина, ${ }^{2}$ А.П. Возняковский, ${ }^{2}$ Ю.А. Фадин ${ }^{1}$ \\ ${ }^{1}$ Институт проблем машиноведения РАН, \\ 199178 Санкт-Петербург, Россия \\ ${ }^{2}$ Научно-исследовательский институт синтетического каучука им. С.В. Лебедева, \\ 198035 Санкт-Петербург, Россия \\ e-mail: spbc63@yandex.ru
}

(Поступило в Редакцию 19 декабря 2016 г. В окончательной редакции 4 марта 2017 г.)

Обсуждается механизм смазочного действия присадок наноалмазов детонационного синтеза в смазочных композициях. Показана зависимость механизма взаимодействия наноалмазов с поверхностями трения от приложенной нагрузки. Предложены две модели смазочного действия наноалмазов и условия их реализации.

DOI: 10.21883/JTF.2017.09.44909.2139

\section{Введение}

В последние три десятка лет исследования возможности применения различных наночастиц в качестве присадок к смазочным композициям пользуются пристальным вниманием. Среди множества применяемых присадок используются и присадки наноалмазов (НА) детонационного синтеза, способ получения которых был разработан во второй половине прошлого века $[1,2]$. Их добавление в качестве присадок в смазочные композиции приводит, как правило, к уменьшению основных трибопараметров (коэффициент трения и износ трибопары), расширяет район используемых температур.

В качестве причин, приводящих к такому результату, рассматривается множество версий [2-16]. Наличие приобретенного при производстве собственного заряда у нанодисперсных частиц, приводящее к упорядочению структуры смазки [2]. Эффект шарикоподшипника, в котором шариками являются НА, катящиеся по поверхности, в которую НА погружены [3]. Образование на поверхности трения наноразмерной субзеренной структуры, чрезвычайно пластические свойства которой приводят к эффективному поглощению энергии фрикционного взаимодействия и ускорению приработки [4]. Образование упорядоченных структур в смазочном масле, содержащем модифицирующие присадки НА шихты, что приводит к изменению физико-химических и к стабилизации реологических характеристик смазки, а увеличение площади фактического контакта - к уменьшению удельной нагрузки [5]. Интенсивная пластическая деформация трибоповерхности НА присадки, приводящая к нанокристалллизации поверхностного слоя и соответственно к его упрочнению, что ускоряет приработку сопряжения [6,7]. Присадка НА увеличивает вязкость при низких температурах, а при высоких работает как шарики, превращая режим скольжения в режим качения [9]. Присадка НА шихты увеличивает вязкость смазки, прочность смазочной пленки и, как следствие, увеличивает ее несущую способность [10]. За- полнение микронеоднородностей на поверхности $[8,10]$. Сложная дисперсная фаза пластичной смазки, в составе которой были и НА шихты, связанные в исходный удерживающий масло каркас, который сначала играет роль стабилизатора смазки, а после некоторого времени работы, когда частицы НА высвобождаются, они, уменьшенные в размере, играют роль противозадирной добавки [11]. Увеличение жесткости трибоповерхности, а также наличие при трении гидродинамической неустойчивости в виде ячеек Бенара в смазке [12]. В [13] отмечают положительный эффект использования присадки НА за счет увеличения вязкости смазки и увеличения твердости предположительно за счет погружения НА в поверхность при трении стальных трибопар, а для трибопар сталь-алюминий - только за счет увеличения вязкости. В [14] полагают, что воздействие НА в смазке на трибоповерхность, приводящее к $\gamma-\alpha$-превращению метастабильного аустенита в мартенсит деформации, является причиной положительного трибоэффекта. В [15] этой причиной считают антипиттинговый эффект НА частиц. В [16] механизмом смазывания с НА считают инкорпорацию НА в трибоповерхность. В литературе встречается и термин „неабразивный алмаз“.

Судя по спектру мнений, на механизм смазочного действия присадок НА нет устоявшихся общепринятых представлений.

В приведенных работах использовались как чистые НА, так и непосредственный продукт детонационного синтеза - наноалмазная шихта, которая содержит дополнительные компоненты и в которой НА присутствуют в виде кластеров фрактального типа [17]. Эти кластеры имеют плотность, отличающуюся от плотности алмаза [18] и значительное количество дефектов структуры, поскольку процесс их образования был далек от равновесного, но это не меняет твердости частиц, составляющих такие агрегаты, поскольку переход на наноуровень размеров частиц алмаза не меняет структуры (геометрии) его кристаллической решетки. Кроме того, такие агрегаты, по крайней мере в исходном состоянии, 
далеки от сферической формы $[9,17]$, чтобы быть шариками в наношарикоподшипниках. Следует учесть и то, что шарики в обычных шарикоподшипниках опираются на поверхность с сопоставимой твердостью, а не на существенно более мягкую, как в случае промышленных стальных трибопар, по которым „катятся“"Н̈А.

Все это плохо согласуется с моделью качения наночастиц в трибозазоре, по крайней мере исходной трибопары, которая при сохранении формы кристаллической решетки частиц НА может привести лишь к абразивному износу, а не наоборот. После приработки исходные НА кластеры шихты, разрушаясь под действием нормальных и сдвиговых напряжений трибозазора, безусловно могут быть более симметричными, но вследствие своей твердости алмаз „неабразивным“ может быть лишь в отношении материалов с такой же твердостью.

Однако факт уменьшения упомянутых трибопараметров налицо. И предлагаемая работа представляет собой еще одну попытку разобраться в механизме смазочного действия присадки НА в смазочных композициях.

\section{Образцы и методика эксперимента}

В работе использовалась трибопара сталь-сталь в наиболее широко используемом сочетании стШХ15-ст45. Твердость сталей определялась с помощью микротвердомера ПМТ-3. Для исследуемого тела ст45 твердость по Виккерсу $H_{V}=328 \pm 6(3218 \mathrm{MPa})$. Для контртела стШХ15 $H_{V}=557 \pm 13(5464 \mathrm{MPa})$. В качестве смазки использовалось индустриальное масло И-40А с присадками шихты НА детонационного синтеза в количествах, mass.\%: $0.08,0.15$ и 0.48. Взвеси готовили ультразвуковым диспергированием. Доля наноалмазов в шихте составляла 56\%. Алмазная шихта была получена в СКТБ „Технолог“ (Санкт-Петербург) по технологии, детально описанной в монографии [19]. Данные по полидисперсности НА шихты представлены в таблице.

Трибоиспытания проводили на стандартной роликовой машине трения ИИ-5018 при скорости скольжения $1 \mathrm{~m} / \mathrm{s}$. Геометрия трибопары цилиндр-цилиндр (показана на рис. 1). Ролик контртела был погружен в ванну со смазкой $(200 \mathrm{ml})$ на $5 \mathrm{~mm}$ и вращался со скоростью $\omega=400 \mathrm{~min}^{-1}$, что соответствовало линейной скорости относительного движения $1 \mathrm{~m} / \mathrm{s}$.

В работе была использована методика, идеология которой заимствована из работы М.М. Хрущева [20], предложившего, в частности, нагружение узла трения последовательно нагрузками $F, 2 F, 3 F$ и т.д., что позволяло измерять изменяющиеся в зависимости от

Среднемассовое $(\mathrm{Mw})$ и среднечисленное $(\mathrm{Mn})$ значения НА

\begin{tabular}{c|c|c}
\hline Диаметр $(D), \mathrm{nm}$ & $\mathrm{Mw}, \%$ & $\mathrm{Mn}, \%$ \\
\hline 178 & 0.25 & 1.72 \\
316 & 77.20 & 93.40 \\
562 & 22.50 & 4.84
\end{tabular}

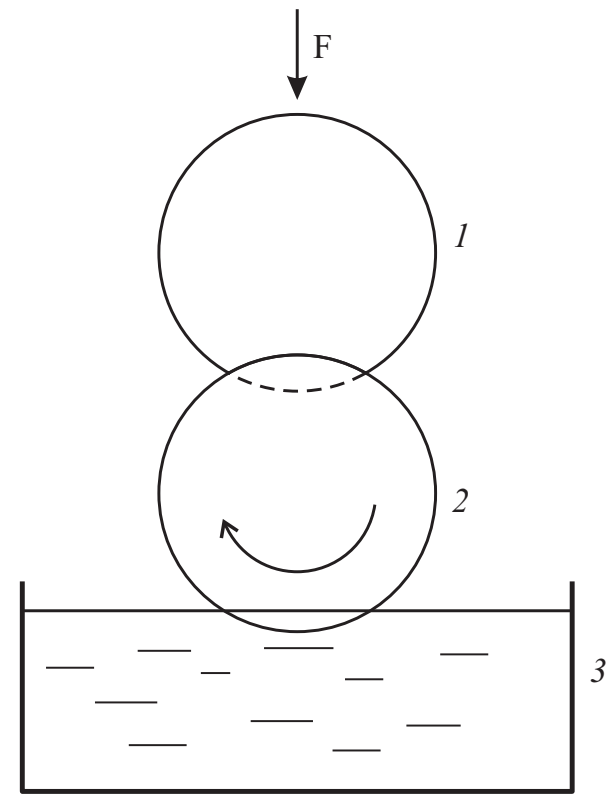

Рис. 1. Схема трибоузла. $1-$ неподвижное исследуемое тело, 2 - подвижное контртело, 3 - ванна со смазкой.

нагрузки износ и давление в контакте трущихся тел. Модификация работы М.М. Хрущева описана в [21], окончательный вид модификции в виде пяти схем трибоиспытаний для получения спектра трибохарактеристик приведен в [22].

В настоящей работе используются лишь две из пяти схем. Первая, когда при ступенчатом нагружении узла трения последовательно увеличивающимися нормальными нагрузками по $100 \mathrm{~N}$ от 100 до $1000 \mathrm{~N}$ на испытуемом образце при первоначальном линейном по образующей цилиндра контакте нарабатывается пятно износа и происходит приработка трибопары. При этом в конце каждой ступени нагрузки измеряется площадь пятна износа. Время испытания на каждой ступени равнялось $5 \mathrm{~min}$. Полученное в конце схемы 1 пятно трибоконтакта нагружается снова (схема 2) такой же последовательностью нагрузок, но без остановки. Изменения площади пятна износа здесь незначительны, и давление в трибоконтакте пропорционально нагрузке. По результатам схемы 1 строятся зависимости от величины нагрузки $F_{N}$ значений коэффициента трения $f$, объемного износа $V_{i}$ на $i$ ступени, суммарной по $i$-ю ступень работы $\Sigma A_{i}$ против сил трения и давления $P_{f}$ в конце каждой ступени нагружения.

По второй схеме строятся в зависимости от давления $P_{s}$ в начале работы ступени нагружения величина $f$, линейная интенсивность изнашивания $I_{h}$ и температура $T$. Подробнее сведения о деталях обработки результатов измерений и расчетах можно найти в [22].

Для измерения площади пятна износа использовался микроскоп МБС-10, для измерения температуры смазочной жидкости - инфракрасный пирометр DT-8816. Перед каждым новым пятном поверхность контртела 
доводилась до чистоты, при которой $R_{a}$ была не хуже $0.15 \mu \mathrm{m}$. Контроль проводился измерителем шероховатости TR200.

Все представленные величины являются средними по результатам испытаний от 3 до 5 пятен для каждой концентрации. При доверительном интервале не хуже 65\% среднеквадратичная ошибка всех представленных параметров укладывалась в $15 \%$.

\section{Результаты и обсуждение}

Результаты, полученные по первой схеме, представлены на рис. $2-5$ в зависимости от нагрузки $F_{i}$. На рис. 2 представлена зависимость коэффициента трения $f$. Отчетливо видно, что уже при наработке пятна износа он существенно ниже для смазки, содержащей присад-

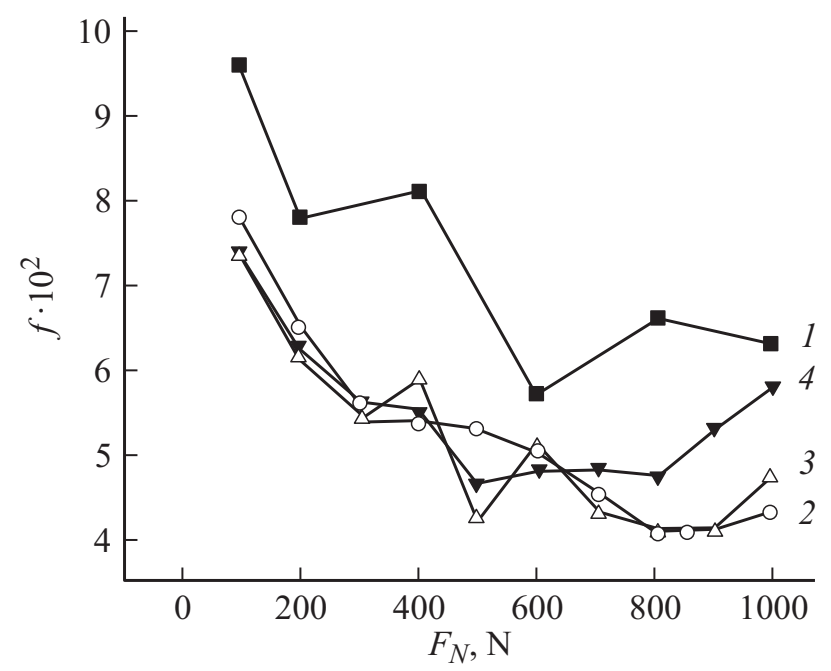

Рис. 2. Зависимость коэффициента трения $f$ от нагрузки $F_{N}$ в процессе нарабатывания пятна износа (схема 1). Концентрации $C$ присадки, mass. $1-0,2-0.08,3-0.15,4-0.48$. Обозначения кривых на всех рисунках одинаковы.

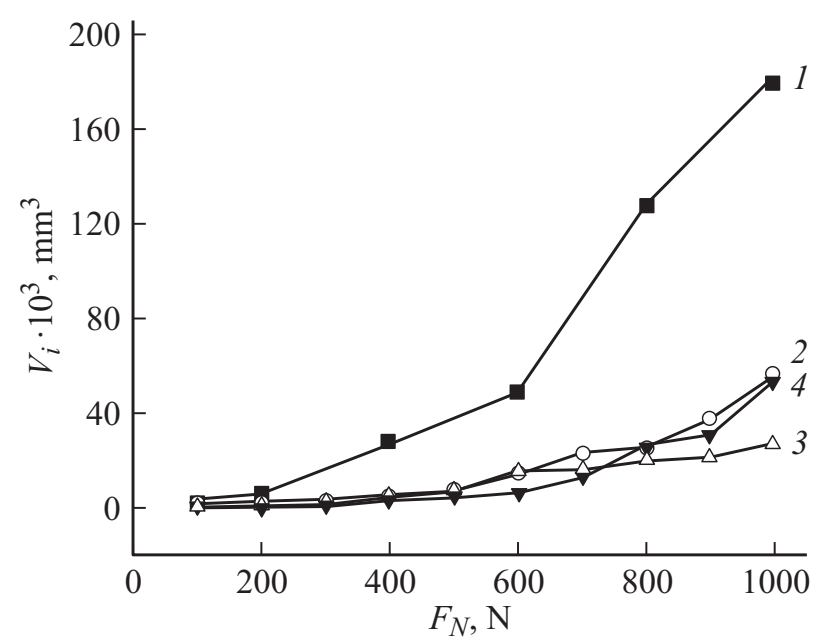

Рис. 3. Зависимость объемного износа $V$ от нагрузки $F_{N}$.

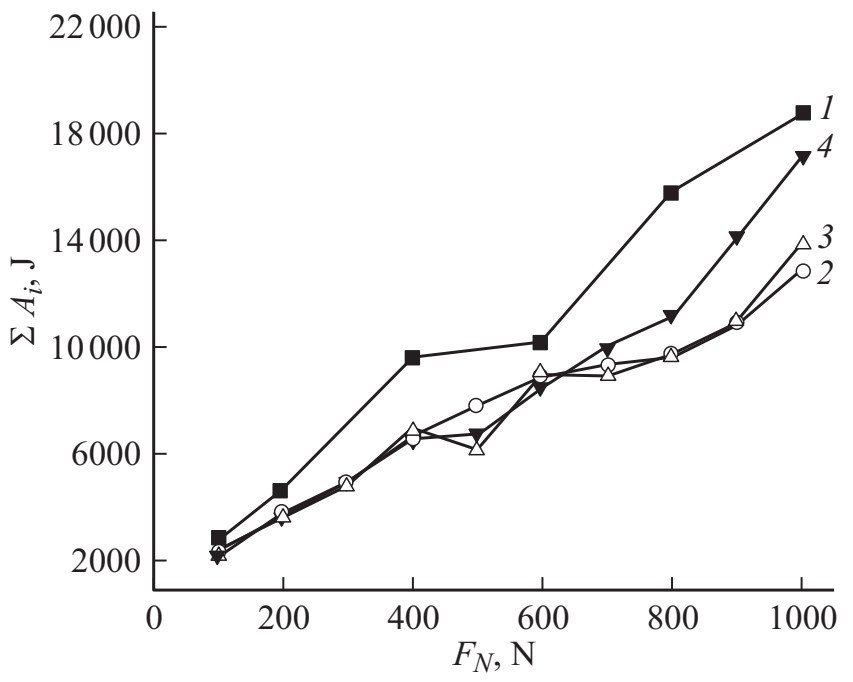

Рис. 4. Зависимость от нагрузки $F_{N}$ суммы затраченных работ $\Sigma A_{i}$ против сил трения по $i$ ступень включительно.

ку НА, что подтверждает уже известные результаты. Однако обращает на себя внимание факт весьма малой зависимости $f$ от концентрации присадки: кривые 2 и 3 в среднем почти совпадают. Еще более отчетливо это видно на зависимости объемного износа $V_{i}$, представленной на рис. 3. Существенно отличаясь от кривой 1 , соответствующей чистому маслу, в сторону уменьшения объемного износа $V_{i}$, кривые $2-4$ тоже почти совпадают. Та же тенденция просматривается и на зависимости суммарной работы $\Sigma A_{i}$ против сил трения (рис. 4). Отметим также, что она для всех трех концентраций присадки не намного меньше работы в масле без присадки. На рис. 5 представлены зависимости давления $P_{f}$ в конце каждой ступени нагрузки. На первый взгляд плохая зависимость от концентрации присадки здесь не просматривается, однако следует обратить внимание на последние точки кривых 2 и 4: они совпадают. Это значит, что площадь наработанного трибоконтакта, с которого и начинается работа по следующей схеме, у этих двух весьма разных концентраций одинакова.

То обстоятельство, что выше некоторой концентрации трибопараметры перестают зависеть от нее, отмечалось и в работах $[3,12,15]$ и эта концентрация составляла $0.1 \mathrm{mass} \%$, хотя в [12] отмечалось, что оптимальная концентрация для разных сталей может быть разной, но тоже не выше $0.1 \%$. В [15] она определена как $0.11 \%$. В других работах это не исследовалось специально,

Такая почти независимость трибопараметров от концентрации присадки заставляет рассмотреть возможные причины этого.

В [2] приведена классификация присадок к смазкам по механизму смазочного действия: 1) поверхностноактивные (адсорбированный граничный слой на поверхности), 2) химически активные (химически связан с поверхностью и имеет пониженное сопротивление сдвигу), 3) нерастворимые в дисперсионной среде, но имеющие 


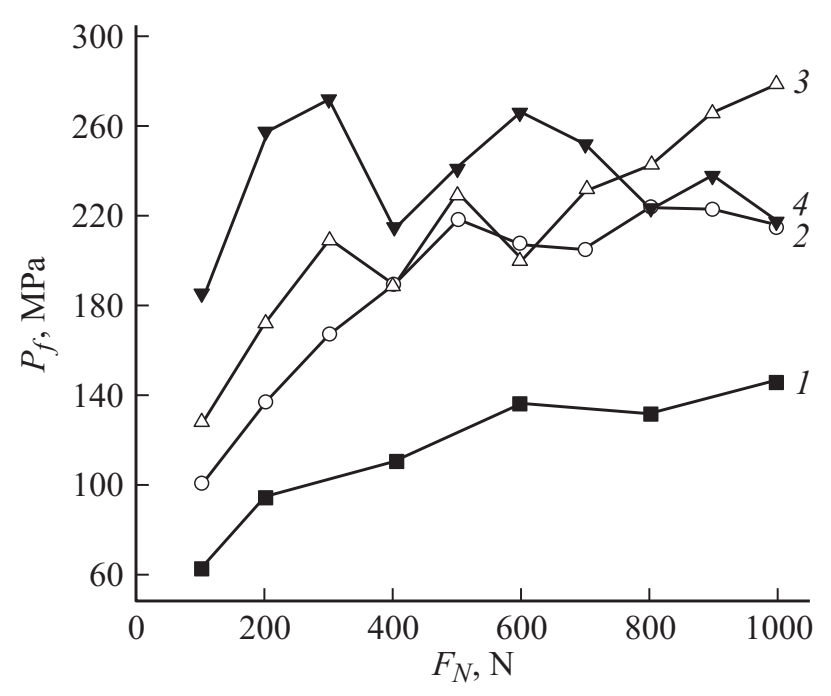

Рис. 5. Зависимость давления на контакте в конце каждой ступени $P_{f}$ от нагрузки $F_{N}$.

слоистую структуру (антифрикционные и противозадирные).

Наноалмазы не укладываются ни в один из пунктов этой классификации. Не работает и ни один из соответствующих механизмов смазочного действия.

Добавка НА, очень жестких и химически неактивных частиц, в смазочную среду принципиально меняет работу смазки. По твердости с НА не может сравниться никакой другой ее компонент, даже если используется смазка с полным комплектом различного рода присадок или пластическая смазка. В нашем случае этими компонентами могут быть компоненты самой присадки - шихты НА. При взаимодействии под нагрузкой НА с металлом трибопары все прочие компоненты смазки будут просто выдавливаться из зоны контакта. Всевозможные модификации НА поверхностно активными веществами $[2,11]$ в трибозазоре не будут определяющими. Более того, попытки связать взвесь диспергированных НА в некую пространственную структуру с повышенной несущей способностью $[2,11]$ в условиях граничного трения не будут успешными из-за несопоставимости прочности связующих с материалом связываемых элементов (НА) и трибопары.

В статике взаимодействие алмаз (НА)-металл под нагрузкой называется индентированием (наноиндентированием [23]) алмаза (наноалмаза) в металл. Оно основано на существенном превосходстве твердости алмаза над твердостью промышленных материалов. В настоящее время макро- и микроиндентирование, регламентированное государственными стандартами (ГОСТ), a также наноиндентирование [23] являются широко распространенными методами измерения твердости. Но это в статике, инденторами определенной формы, при небольших нагрузках и это заведомо обратимо. Однако и шлифование, и полирование алмазными абразивами являются обратимым индентированием, если не считать отдельных частиц, даже в этом случае остающихся на обрабатываемой поверхности [24].

В трибозазоре, смазываемом маслом с НА присадкой, при малых нагрузках НА частицы тоже сначала обратимо индентируются, деформируя, но не задерживаясь в деформируемом материале, работая как абразив, полируя поверхность. Однако при последовательном увеличении нагрузки через достаточно короткие промежутки времени наступает необратимость процесса наноиндентирования. Частицы НА будут застревать в металле. Начнется формирование сплошного слоя индентированных (шаржированных, вдавленных) в поверхность трения частиц НА. Сначала это произойдет с телом, имеющим меньшую твердость, а после или по мере формирования на нем сплошного слоя НА в менее твердом триботеле и достаточного увеличения нагрузки этот процесс начнется и в более твердом контртеле. В конечном итоге, когда на обеих трущихся поверхностях сформируются сплошные слои индентированных НА частиц, трибопара сталь-сталь превратится в трибопару алмаз-алмаз, смазываемую остальными компонентами смазки и имеющую наименьший износ.

Отметим, что именно при таком процессе практическая независимость от концентрации присадки и будет иметь место, поскольку важен лишь сам факт наличия НА. От концентрации, а также обязательно от величины нагрузки, при которой процесс примет необратимый характер, будет зависеть только плотность образования сплошного слоя индентированных НА. При более высокой концентрации она будет большей, но при заполнении всей трибоповерхности увеличение концентрации шихты или частиц НА уже ничего не изменит.

Одновременно именно в трибопаре алмаз-алмаз взвешенные в смазке НА условно могут быть рассматриваемы как „шарики“ в наношарикоподшипнике, поскольку опорная поверхность будет иметь практически ту же твердость.

Здесь следует оговориться, что данная модель предложена для условий, когда в качестве присадки используются только НА, как это было в работах $[3,9,12,13,16]$, а не шихта НА [2,4-8,14,15]. В случае использования шихты процесс взаимодействия с трибоповерхностью заканчивается тем же, но формирование трибослослоя индентированных НА происходит сложнее.

Наиболее отчетливо работа предложенной модели была продемонстрирована в [3], где была исследована взвесь НА в парафиновом масле. Авторы показали, что НА частицы сначала полируют трущиеся поверхности, а затем погружаются в них, предотвращая их контакт. Были приведены снимки просвечивающей электронной микроскопии, на которых отчетливо виден слой НА, индентированных в поверхность. Одновременно приведены и результаты рентгеновской фотоэлектронной спектроскопии, где пик, соответствующий алмазу, и пик от поверхности, обработанной НА, совпадали. Это позволило авторам считать, что взвешенные НА частицы работают как шарики в шарикоподшипнике (хотя „шарики“ являются, скорее, многранниками), уменьшая износ 
и коэффициент трения. Пока это единственная работа, в которой наиболее отчетливо приведены прямые доказательства высказанной авторами (и нами) точки зрения.

То, что НА вдавливаются в трибоповерхность, отмечалось и в работах $[13,16]$, не исключалось этого и в [2], но лишь предположительно.

Описанная модель может не работать, когда рабочая нагрузка недостаточна для необратимого индентирования. Так, в [12], используя спектроскопию комбинационного рассеяния, исследовали $s p^{3}$-структуру углерода на тертой с присадкой НА поверхности и не нашли скольнибудь заметного пика между 1000 и $2000 \mathrm{~cm}^{-1}$. При этом трибопараметры улучшались, поскольку увеличивалась жесткость поверхности.

Давление, при котором индентирование становится необратимым, является функцией твердости трущейся поверхности. Это означает, что при трении с НА присадкой в [12] усилие было недостаточным для необратимого индентирования НА в поверхность трения. Если при этом достаточно долго проводить трибопроцесс, а снималась зависимость трибопараметров от времени при постоянной нагрузке, то вступает в силу другой механизм ужесточения поверхности металлов, тоже приводящий к положительным триборезультатам.

Известно [25], что предел прочности, твердость и ряд других физических параметров при механической обработке, приводящей к уменышению величины кристаллических зерен, увеличиваются. В [26] были перечислены методы воздействия на металлические поверхности, вызывающие интенсивную пластическую деформацию, приводящую к нанокристаллизации этих поверхностей. Среди них рассматривались вибрационный наклеп шариками, пескоструйная обработка, обработка металлической щеткой, ультразвуковая ударная обработка и прокатка колес по железнодорожным рельсам. В последнем случае толщина деформированного слоя достигала $3 \mathrm{~mm}$, а наибольшая пластическая деформация доходила по глубине до $500 \mu \mathrm{m}$. Все эти методы в настоящее время успешно используются для упрочнения несущих поверхностей [26].

Наноалмазы, используемые в смазочных композициях, при недостаточной для необратимого индентирования нагрузке, прокатываясь или скользя и пластически деформируя поверхность, как раз и выполняют ту функцию, которая приводит к нанокристаллизации и упрочнению трибоповерхностей. Иначе говоря, использование НА в качестве присадки в смазочных композициях при умеренных нагрузках - это еще один способ упрочнения поверхности, при котором происходит нанокристаллизация и упрочнение поверхностного слоя.

Факт упрочнения поверхности при использовании присадки НА отмечался во многих работах $[2,3,5-7,12,13]$. При этом, чем дольше это происходит, тем прочнее становится трибоповерхность, тем большая нагрузка потребуется для необратимого индентирования НА.

В этих работах фиксировали изменения во времени коэффициента трения или износа при небольших по- стоянных нагрузках, недостаточных для необратимого индентирования. Зато экспозиции были до часов. При такой длительной обработке НА поверхностей трения наступало именно деформационное упрочнение трибоповерхности. Однако ни при каком упрочнении твердость стали не достигнет твердости алмаза. Поэтому алмаз или НА под нагрузкой всегда будут индентироваться в сталь, а обратимо или необратимо - это в зависимости от нагрузки.

Более того, при каждой нагрузке, недостаточной для необратимого индентирования, по-видимому, существует предел увеличению твердости при обработке трибоповерхности НА, после которого НА будут уже играть роль только абразива вследствие большей твердости. Так, в [7] при использовании присадки НА шихты в работе закаленной стальной трибопары износ при работе с присадкой оказался выше, чем при смазывании базовым маслом.

В значительном количестве работ в качестве присадки к смазочным композициям (как жидким, так и консистентным) использовалась НА шихта $[2,4-7,11,14]$. Кроме того, что в ней кроме НА присутствуют другие формы углерода, в первую очередь графит, в том числе и ассоциированный с НА кластерами, сами эти фрактальные кластеры при работе в трибозазоре не будут устойчивыми образованиями, а под действием нормальных и касательных напряжений будут разрушаются до равновесных при каждой используемой нагрузке размеров. И до, и после формирования сплошных индентированных слоев НА этот процесс затронет и все остальные НА частицы, взвешенные в масле и попадающие в трибозазор. Это приведет в конечном итоге к тому, что взвешенные в масле НА частицы будут иметь устойчивые при каждой используемой нагрузке размеры. Эти устойчивые размеры при различных нагрузках будут разными, и чем больше будет нагрузка, тем меньше будет устойчивый размер взвешенных в смазке НА кластеров. И здесь, по-видимому, тоже существует предел, который можно определить по размеру индентированных (если позволяет нагрузка) в трибоповерхность частиц НА. Форма же оставшихся взвешенными в смазке частиц НА будет значительно симметричнее и напоминать сферу, но ее поверхность будет отнюдь не гладкой поверхностью сферы, а, скорее, будет напоминать головную часть булавы, что может драматично сказаться при значительном увеличении нагрузки, поскольку оставшиеся взвешенными в смазке такие частицы будет стимулировать обратный индентированию процесс, тем более что вдавленные в поверхность частицы НА ничем практически с ней не связаны.

Отметим также, что процесс наноиндентирования при трении затронет в обязательном порядке оба компонента трибопары, из чего следует, что оптимальной трибопарой в таких условиях будет такая, когда оба ее компонента будут иметь одинаковую и не слишком большую твердость. В этом случае процесс наноиндентирования будет происходить с одинаковой скоростью одновре- 
менно в оба трущихся компонента, и результирующее трибопокрытие будет одинаково связано с основанием.

По двум причинам твердость двух поверхностей, трущихся со смазкой, содержащей НА, не должна быть очень большой и сильно различаться.

1. Давление, при котором индентирование будет необратимым для менее твердого компонента трибопары, может не быть достаточным для более твердого. Это приведет к более сильному износу более твердого контртела при трении об уже сформировавшееся на более мягком теле НА покрытие. И хотя одновременно с формирующимся НА покрытием более мягкого триботела происходит деформационное упрочнение поверхности более твердого контртела $[25,26]$, тем не менее его износ при трении об это покрытие из НА будет сильнее.

2. При очень сильном различии твердости (например, закаленная сталь-алюминий) покрытие из индентированных НА может не образоваться ни при каких условиях. В алюминии потому, что НА не достаточно прочно в нем застрянут и при трении будут перемещаться в самом металле, приводя к повышенному его износу. В стали же потому, что нет более прочного покрытия у второго компонента трибопары. В самой же стали происходит поверхностное упрочнение [26]. В [13] испытали именно такую трибопару. Твердость стали при этом почти в пять раз превосходила твердость A1. $\mathrm{B}$ результате износ $\mathrm{Al}$ увеличивался при использовании смазки, содержащей присадку из НА, по сравнению с базовым маслом.

Использование шихты НА имеет ряд особенностей. Фрактальные кластеры, в которые „упакованы“ НА, могут достигать размеров порядка единиц микрометров. Плотность НА фрактальных кластеров $\rho_{f c}=3-3.1 \mathrm{~g} / \mathrm{cm}^{3}[18,27]$, что составляет $88 \%$ от плотности алмаза [18]. Это означает, что кластеры НА имеют достаточно большое количество внутренних пустот. В [27] была изучена агрегационная устойчивость этих структур при ультразвуковом диспергировании в различных жидкостях. В неполярных жидкостях, как выяснилось, в отличие от полярных диспергирование не приводит к уменьшению устойчивости агрегатов. Однако в трибозазоре нормальные и касательные усилия, прикладываемые к диспергированным в смазку частицам, содержащим НА, намного превосходят те усилия, при которых кластеры разрушаются в процессе диспергирования в полярных жидкостях. Из этого следует, что процесс разрушения остаточных после диспергирования кластеров до устойчивых при каждой данной нагрузке размеров в трибозазоре будет обязательным явлением.

В настоящей работе, как уже говорилось, была использована шихта НА. На рис. 6, 7 представлены результаты испытаний по схеме 2, когда исследуется трение в приработанной трибопаре. Приведены зависимости от начального давления $P_{s}$ коэффициента трения $f$ и линейной интенсивности изнашивания $I_{h}$. Построение зависимостей от давления позволяет получить оценку несущей способности материала, оценку предела нагружения данного трибоузла. Зависимость от концентрации

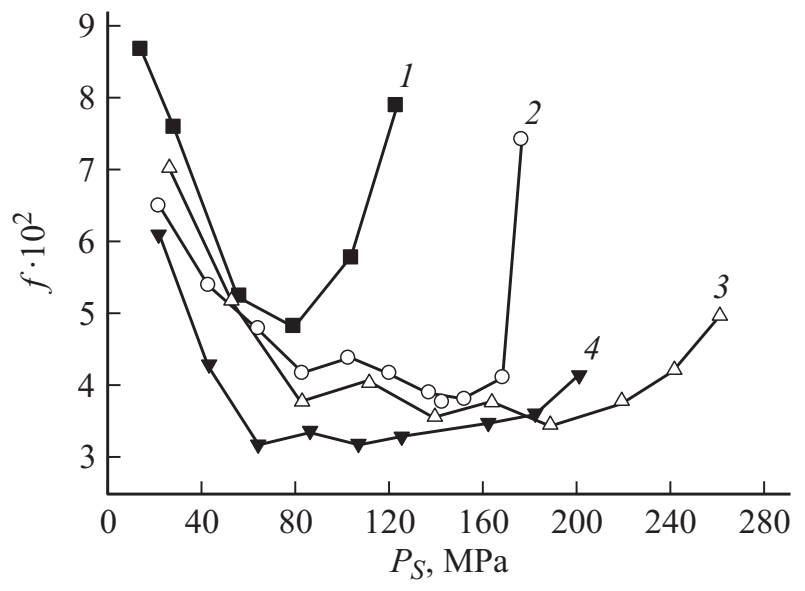

Рис. 6. Зависимость коэффициента трения $f$ от начального давления $P_{S}$.

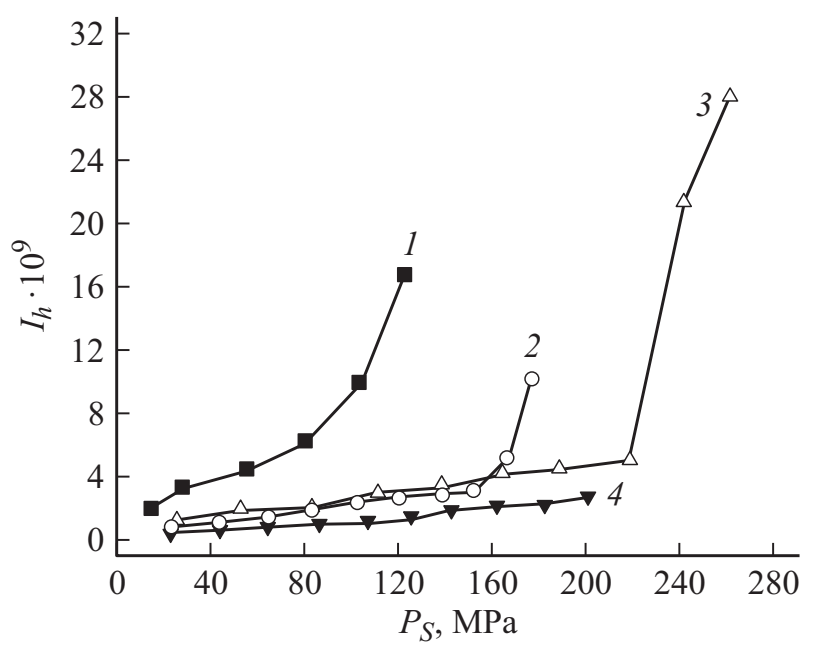

Рис. 7. Зависимость линейной интенсивности изнашивания $I_{h}$ от начального давления $P_{S}$.

присадки на рис. 6 и 7 проявляется четче, что, вероятнее всего, свидетельствует о зависимости качества индентированного НА покрытия.

Как следует из рисунков, и коэффициент трения, и линейная интенсивность изнашивания существенно меньше для масла с присадкой шихты НА. Равно как и диапазон рабочих давлений намного шире.

При работе по схеме 2 стационарный режим выдерживался до определенной нагрузки, определяемой несущей способностью исследуемого материала трибопары, после чего режим ступенчатой нагрузки был сделан прерывистым, как по схеме 1. Это было необходимо для того, чтобы наметившийся переход к разрушению покрытия и интенсивному абразивному износу не перешел в неконтролируемую стадию, а был лишь обозначен.

Кривая 2 на рис. 6, соответствующая самой малой концентрации присадки, при высоких давлениях уходит резко вверх, подтверждая начало обратного индентированию процесса. Этот процесс обозначился и на кривых 


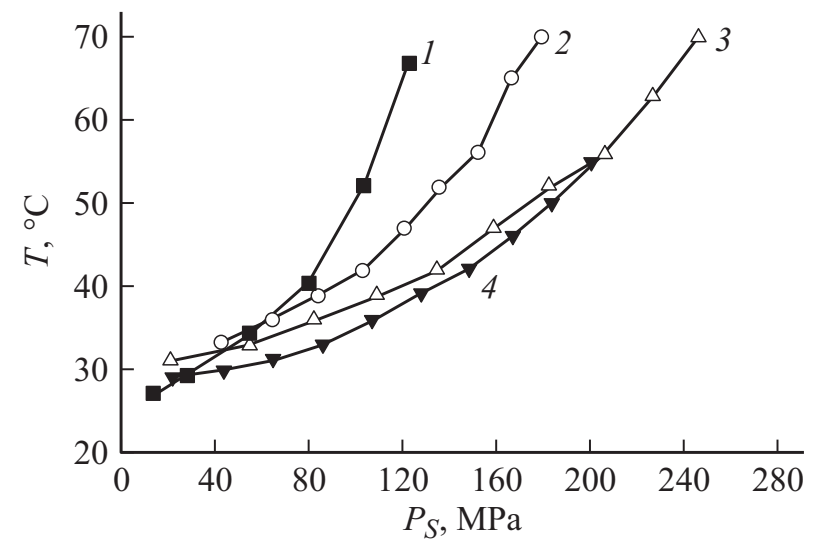

Рис. 8. Зависимость температуры смазочной жидкости от начального давления $P_{S}$.

для двух других концентраций, но в разной мере: на кривой 3 он отчетливее и это подтверждается рис. 7, из которого следует, что если для кривой 3 обратный процесс уже имеет место, то для кривой 4 это лишь самое начало.

Индентированные наночастицы алмаза не связаны с металлом трибопары ни структурно, ни химически. Они вдавлены в него. Адгезивная составляющая этого контакта не будет определяющей. Поэтому при повышении давления и соответственно увеличении касательных усилий в трибозазоре обратный процесс неизбежен. Взвешенные в смазке наночастицы алмаза, не являющиеся гладкими шариками, начнут вырывать индентированные наночастицы. Процесс очень быстро принимает характер катастрофического абразивного износа. Последнее означает, что для каждого материала, используемого в трибопаре, в случае использования смазки с присадкой НА при трении скольжения следует тщательно определять несущую способность покрытия из индентированных частиц НА.

Как следует из рис. 7, при используемых нагрузках наиболее устойчивым оказалось покрытие, наработанное с концентрацией, соответствующей кривой 4.

На рис. 8 приведены температурные зависимости, из которых следует, что при значительно большем давлении температура может быть не выше, если используется присадка, а не базовое масло. И здесь наиболее отчетливо это демонстрирует кривая 4.

Отдельно следует рассмотреть ситуацию в трибозазоре при трении качения. Она может быть принципиально иной, поскольку касательные усилия в трибозазоре при трении качения существенно меньше, чем при трении скольжения. При работе такой трибопары принципиально возможно более быстрое образование значительно более устойчивого покрытия из индентированных НА присадки. Это, в свою очередь, приведет и к меньшему износу, и к существенно большей несущей способности элементов трибопары, и к большей долговечности трибоузла.
Подводя итог, следует выделить две основных причины улучшения трибопараметов при использовании присадки НА (или шихты НА) в смазочных композициях. Рассматриваем лишь стальные трибопары.

1. Увеличение твердости поверхности вследствие уменьшения величины зерна в результате пластической деформации, вызванной действием частиц НА. Вариант годится для сочетаний твердости элементов трибопары в широком диапазоне. Однако он хорош лишь как приработочный, поскольку при достижении предела твердости, определяемого как нагрузкой, так и временем обработки, присадка начнет работать как абразив. Этот вариант и более легко реализуем.

2. Превращение исходной трибопары в трибопару алмаз-алмаз, при котором можно сохранять условия смазывания, поскольку алмазная трибоповерхность будет пригодна для реализации модели наношарикоподшипника. Однако для трибопар скольжения этот вариант труднее реализуем, чем для трибопар качения. И кроме того, оптимальной трибопарой в этом случае будет трибопара с минимальным различием твердости поверхностей и с твердостью, при которой достаточно легко достижимо усилие, необходимое для необратимого индентирования частиц НА.

\section{Заключение}

1. Проведен анализ взаимодействия присадки НА в смазочных композициях со стальными поверхностями трибопар.

2. Сформулированы две основных причины, приводящие к улучшению трибопараметров, и определены границы их применения.

3. Показана определяющая роль нагрузки при реализации предложенных моделей развития событий при трении и смазке с присадками НА или шихты НА.

\section{Список литературы}

[1] Долматов В.Ю. Ультрадисперсионные алмазы детонационного синтеза. СПб.: Изд-во СПбГПУ, 2003. 345 с.

[2] Витязь П.А., Жорник В.И., Ильющенко А.Ф., Сенють В.Т., Комаров А.И., Коржсеневский А.П., Ивахник А.В. Наноалмазы детонационного синтеза: получение и применение. Минск: Беларус. навука, 2013. 381 с.

[3] Tao X., Jiazheng Z., Kang X. // J. Phys. D: Appl. Phys. 1996. Vol. 29. N 11. P. 2932-2937.

[4] Витязь П.А., Жорник В.И., Кукареко В.А. Наноструктурные материалы-2004. Беларусь-Россия. Минск, 2004. C. $72-76$.

[5] Витязь П.А., Жорник В.И. Трибофатика. Сб. докл. V Междунар. симпозиума по трибофатике. Иркутск, 2005. С. 7179.

[6] Витязь П.А., Жорник В.И., Кукареко В.А. Трибофатика. Сб. докл. V Междунар. симпозиума по трибофатике. Иркутскб 2005. С. 80-87.

[7] Витязь П.А., Жорник В.И., Кукареко В.А., Камко А.И. // Трение и износ. 2006. Т. 27. № 1, С. 61-68. 
[8] Витязь П.А., Жорник В.И., Кукареко В.А., Камко А.И. // Трение и износ. 2006. Т. 27. № 2. С. 196-200.

[9] Wu Y.Y., Tsui W.C., Liu T.C. // Wear. 2007. Vol. 262. P. 819825.

[10] Долматов В.Ю. // Успехи химии. 2007. Т. 76. № 4. С. 375397.

[11] Жорник В.И., Ивахник А.В. Наночастицы в конденсированных средах. Сб. науч. ст. Минск: Изд. центр БГУ, 2008. C. 66-71.

[12] Hsiao Yeh Chu, Wen Chen Hsu, Jen Fin Lin. // Wear. 2010. Vol. 268. P. 1423-1433.

[13] Chou C.C., Lee S.H. // Wear. 2010. N 269. P. 757-762.

[14] Белоцерковский М.А., Жорник В.И., Кукареко В.А., Камко А.И. // Упрочняющие технологии и покрытия. 2010. № 5. С. 34-38.

[15] Жорник В.И., Ивахник А.В., Ивахник В.П. // Механика машин, механизмов и материалов. 2010. № 3. С. 85-92.

[16] Elomaa O., Hakala T.H., Myllymäki V., Oksanen J., Ronkainen H., Singh V.K., Koskinen J. // Diamond \& Related Materials. 2013. Vol. 34. P. 89-94.

[17] Сакович Г.В., Губаревич В.Д., Бадаев Ф.З., Брыляков П.М., Беседина О.А. // ДАН СССР. 1990. Т. 310. № 2. С. 402404.

[18] Барабошкин К.С., Губаревич Т.М., Комаров Ф.М. // Коллоид. журн. 1992. Т. 54. № 6. С. 9-12.

[19] Долматов В.Ю. Детонационные наноалмазы. Получение, свойства, применение. СПб.: НПО Профессионал, 2011. $536 \mathrm{c.}$

[20] Хрущов М.М. Исследование приработки подшипниковых сплавов и цапф. М.Л.: Изд. АН СССР, 1946. 160 с.

[21] Гинзбург Б.М., Точильников Д.Г. // ЖТФ. 2001. Т. 71. Вып. 2. С. 120-124.

[22] Точильников Д.Г., Гинзбург Б.М. // Вопросы материаловедения. 2002. Т. 31. № 3. С. 39-48.

[23] Головин Ю.И. Наноиндентирование и его возможности. М.: Машиностроение, 2009. 312 с.

[24] Бакли Д. Поверхностные явления при адгезии и фрикционном взаимодействии. М.: Машиностроение, 1986. 360 с.

[25] Армстронг Р.В. В сб.: Сверхмелкое зерно в металлах / Под ред. Л.К. Гордиенко. М.: Металлургия, 1973. С. 1140.

[26] Васильев М.А., Прокопенко Г.И., Филатова В.С. // Успехи физ. мет. 2004. Т. 5. С. 345-399.

[27] Агибалова Л.В., Возняковский А.П., Долматов В.Ю., Клюбин В.В. // Сверхтвердые материалы. 1998. № 4. C. 87-95. 